by means of Avogadro's number, an easy calculation $\left(x=60.62 \times 10^{22}\right.$ $\times 1.7 \times 10^{-27}=1.03 \times 10^{-3}$ ) indicates the presence of only one solitary positive or negative ion of mercuric sulfide in each 1000 liters of the solution. Surely, in order to maintain equilibrium with anything in this volume, these two ions would have to move with the velocity of light, and be everywhere at the same time; and this condition we know they do not fulfil.

CONTRIBUTION FROM THE UNIVERSITY OF WASHINGTON, G. McP. SMiтн Seatthe, Washington

Received April 17, 1922

[Contributron from the Chemical Laboratory of the Universtity Colifege of Science of Calcutta]

CONSTITUTION OF THE SO-CALLED DITHIO-URAZOLE OF MARTIN FREUND. I

By Praphulita Chandra Guha

Received January 31, 1921

Freund and Wischewiansky ${ }^{1}$ showed that by treating hydrazo-dithiodicarbonamides of the type RNH.CS.NHNHCS.RNH with phosgene in toluene solution, a molecule of hydrogen sulfide is eliminated and compounds of the formula $\mathrm{C}_{2} \mathrm{H}_{2} \mathrm{R}_{2} \mathrm{~N}_{4} \mathrm{~S}$ are formed for which the constitutional formula, RHN. $\underbrace{\mathrm{C}}_{\mathrm{NR}}$ or $\mathrm{RN}: \mathrm{C} \underbrace{\mathrm{C}}_{\mathrm{NR}}$.SH containing a triazole ring was given.

Later on, Freund with his collaborators ${ }^{2}$ showed that when the hydrazodithio-dicarbonamides of the above type were treated with strong hydrochloric acid, instead of phosgene, the decomposition took place in two ways, yielding compounds of the formulas $\mathrm{C}_{2} \mathrm{H}_{2} \mathrm{RN}_{3} \mathrm{~S}_{2}$ and $\mathrm{C}_{2} \mathrm{H}_{2} \mathrm{R}_{2} \mathrm{~N}_{4} \mathrm{~S}$, respectively, the former by the loss of one molceule of $\mathrm{NH}_{3}$ or $\mathrm{NH}_{2} \mathrm{R}$, as the case may be, and the latter by the loss of one molecule of $\mathrm{H}_{2} \mathrm{~S}$, the former was acidic and the latter basic in nature.

The formation of the compound $\mathrm{C}_{2} \mathrm{H}_{3} \mathrm{~N}_{3} \mathrm{~S}_{2}$ of acid nature, was evidently assumed to be represented by the following equation.

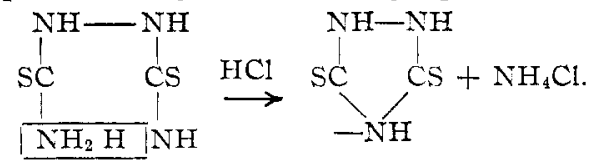

Dithio-urazole

\footnotetext{
${ }^{1}$ Freund and Wischewiansky, Ber., 26, 2877 (1893).

${ }^{2}$ Freund, ibid., 27, 1744 (1894). Freund and Imgart, ibid., 28, 946 (1895). Freund and Heilbrun, ibid., 29, 859 (1896).
} 
and that of the basic compound $\mathrm{C}_{2} \mathrm{H}_{4} \mathrm{~N}_{4} \mathrm{~S}$ by<smiles>N=C(N)N[Hg]</smiles>

\section{Iminothio-urazole}

Freund and Imgart assumed the above dithio-urazole formula for the former, although they did not adduce any experimental evidence in favor of the view.

In their opinion, (1) it contained two atoms of hydrogen replaceable by metals; (2) it was deprived of two atoms of hydrogen by the action of mild oxidizing agents, $e$. g., hydrogen peroxide, ferric chloride and iodine, to give a compound of the azo or disulfide formula<smiles>N1N[Se]N1</smiles>

(Azo formula)<smiles></smiles>

(Disulfide formula)

However, credit must be given to Max Busch and Schmidt ${ }^{3}$ who in their attempt to prepare a derivative of aminocarbo-di-imide $\mathrm{NH}: \mathrm{C}: \mathrm{N} \cdot \mathrm{NH}_{2}$ have incidentally criticized the dithio-urazole formula of Freund and Imgart and suggested the correct formula established in this paper.

The present author has succeeded in proving that (1) Freund's dithiourazole contains only one atom of hydrogen replaceable by such metals as potassium, sodium or silver; (2) it loses only one atom of hydrogen, and not two, from one molecule, when it is treated with ferric chloride, hydrogen peroxide and iodine, and forms a disulfide of the formula $\left(\mathrm{C}_{2} \mathrm{H}_{2} \mathrm{~N}_{3} \mathrm{~S}\right)-\mathrm{S}-\mathrm{S}-\left(\mathrm{C}_{2} \mathrm{H}_{2} \mathrm{~N}_{3} \mathrm{~S}\right)$. Experimental evidence in support of this double disulfide formula has been furnished by the actual estimation of the iodine required for the oxidation of a known quantity of the so-called dithio-urazole; and also by taking the molecular weight of the disulfide of allyldithio-urazole (?) by ebullioscopic method (m. w. 344). The disulfides of phenyldithio-urazole (?) and of dithio-urazole (?), are insoluble in all ordinary solvents and so the determination of their molecular weights was not possible. Freund's azo or disulfide formula ${ }^{4}$ can therefore now be safely discarded.

As regards the behavior of dithio-urazole towards acetic anhydride, Freund merely called it "characteristic," and made no effort to explain the peculiar behavior. He did not point out definitely the positions in the molecule which were occupied by the acetyl groups of the diacetyl com-

"Busch and Schmidt, Ber., 46, 2240 (1913).

${ }^{4}$ Freund and Imgart, Ref. 2, p. 947. 
pound; but it is apparent, in view of the dithiol formula, that the acetyl groups were supposed to be attached to the sulfur atoms of the thiol groups.

It has been found however, that the diacetyl compound is very unstable and when subjected to even mild treatment, e. g., boiling with water or with dil. acid or heating slightly above its melting point, it loses one of its acetyl groups, forming the stable mono-acetyl derivative. There is no reason, on the basis of the dithiol formula, why one acetyl group should behave so differently from the other and why one should be so stable and the other so unstable towards hydrolytic reagents.

To explain these difficulties, the present author proposes the following formula for Freund's dithio-urazole,<smiles></smiles><smiles>Nc1nncs1</smiles>

and regards it as 5-amino-2-thiol-1,3,4-thiodiazole. In his opinion, it is formed from hydrazo-dithio-dicarbonamide, as follows.

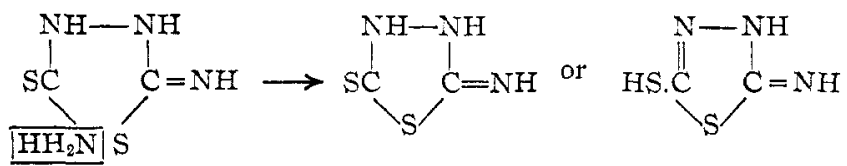

It will be noticed that the parent substance, $\mathrm{NH}_{2} \mathrm{CSNHNHCSNH}$, is assumed to react here in the mono-thiol form, as in the formation of iminothio-urazole (see p. 1503), since (1) according to the new formula there is only one sulfhydrate group present in the molecule and the mono salts are formed by replacing the thiol hydrogen; (2) in the light of the present formula the action of ferric chloride, hydrogen peroxide or iodine is simply to remove two mercaptan hydrogen atoms from two molecules of 5 -amino2-thiol-1,3,4-thiodiazole, yielding the disulfide.<smiles></smiles>

The new thiodiazole formula not only explains the peculiar behavior of acetic anhydride towards it, but also opens up a number of possibilities for the existence of different di-derivatives which have actually been prepared. It is clear from this formula, that the diacetyl derivative has one acetyl group attached to the mercaptan sulfur and the other to the amino or to the imino nitrogen and, as is usual, the former acetyl group is easily hydrolyzed, while the latter is left quite unimpaired.

Additional support is given to this view by the behaxior of the monoacetyl compound towards iodine, alkali and alkyl iodides. With iodine, it gives the diacetyl-disulfide; with alkalies it forms mono salts, and with 
alkyl iodides the acetyl alkyl derivatives. It has also been found that by oxidation of the acetyl-thiodiazole compound and by acetylating the disulfide of the thiodiazole, the same diacetyl-thiodiazole-disulfide is obtained.

It was found by the previous workers that only a mono-dkyl derivative is formed, and all efforts towards the preparation of the dialkyl derivative (analogous to the diacetyl compound, $\mathrm{C}_{2} \mathrm{HN}_{3}=\left(\mathrm{SCOCH}_{3}\right)_{2}$, as it was then supposed to be) were unsuccessful; they found, moreover, that the mono-alkyl derivative was insoluble in alkali and was indifferent towards iodine. According to the old formula, these reactions were certainly abnormal, for the mono-alkyl compound was then represented by the formula, MeS. $\|_{\mathrm{NH}}^{\mathrm{C}}$. $\mathrm{SH}$, and there was still another $-\mathrm{SH}$ group assumed to be present in the molecule which should react with iodine, alkali and alkyl iodide.

To obviate this difficulty, Freund and Imgart ${ }^{4}$ presented the tautomeric formula, HS. C ${ }_{\mathrm{NH}}^{\mathrm{C}}$ ' No amino or imino mercaptan of the type - NH.CS.NH - is known, however, which does not form a thioether, $-\mathrm{N}=\mathrm{C}-\mathrm{S}-\mathrm{R}$, with an alkyl iodide in presence of alkali.<smiles>CN</smiles>

In the light of the new thiodiazole formula, all of these points can be explained most satisfactorily. There is only one mercaptan hydrogen present and when this is replaced by an alkyl group, it cannot react with iodine and alkali or add another alkyl group. In the mono-acetyl compound, the acetyl group has replaced the hydrogen of the amino group, leaving the mercaptan group free and so there is no interference with the latter's normal behavior towards iodine, alkali and alkyl iodide. Had the compound in question really been of dithio-urazole structure, it would certainly give a dialkyl derivative; for, working in the corresponding urazole series, S. F. Acree has prepared many dialkyl derivatives (such as dimethyl, ethylmethyl, diethyl) of phenyl-urazole; moreover the typical dimercaptans, e. g., PhNH. NH. CSSH (or rather, PhNH.N:C $[\mathrm{SH}]_{2}$ ) and 2,5-dithiol-1,3,4-thiodiazole readily yield dialkyl ethers.

The mono-alkylated compound has been found to react with acetic anhydride to yield the same alkyl-acetyl compound as is obtained by a1kylating the mono-acetyl compound.

The behavior of the compound towards mercuric nitrite has also been 
found to be quite in agreement with the new thiodiazole formula. It has been shown $n^{5}$ that mercuric nitrite gives a simple mercaptide nitrite, $\mathrm{RSHgNO}$, with such mercaptans as R-SH; with amino or imino mercaptans (potential mercaptans) it gives compounds of the general formula $\mathrm{RN}=\mathrm{C}-\mathrm{S}(=\mathrm{HgO})-\mathrm{HgNO}_{2}$; and with dimercaptans, e. g., 2,5-dithiol-1,3,4-

thiodiazole it forms compounds of the general formula $\left[\right.$ S.C ${ }_{S}^{\text {C.S }} \mathrm{Hg}_{2} \mathrm{O}$.

In the present instance a compound, $\left(\mathrm{C}_{2} \mathrm{H}_{2} \mathrm{~N}_{3} \mathrm{~S}\right) \cdot \mathrm{SHgNO}_{2}$, has been obtained by the action of mercuric nitrite. This shows that the substance is simply a monomercaptan and does not possess any other group such as $-\mathrm{NHCSNH}-$.

The reason for assigning to one sulfur atom a position in the ring is that the sodium salt (the mono salt) of N-ethyl dithio-urazole (?) on boiling with mercuric oxide for 3 hours ${ }^{6}$ could not be desulfurized, and the unchanged sodium salt was isolated from the reaction mixture. Had there been one atom of sulfur present as $=\mathrm{CS}$, the compound would certainly have exchanged the thioketonic sulfur for an atom of oxygen. In fact, this method of ascertaining the position of sulfur in two isomeric compounds, namely, 1,2-diphenyl-2-thio-5-thiol-2,3-dihydrotriazole and 3-pheny1-2-phenylimido5-thio1-2,3-dihydro-1,3,4-thiodiazole, has been made use of by Max Busch and Wolpert. ${ }^{7}$ These two compounds were prepared by them from the same substances, phenyl-dithio-carbazinic acid and phenyl mustard oil, by changing only the conditions of the experiment. They are, therefore, derivatives of dithio-urazole and thiodiazole, respectively. It is now clear that in Freund's reaction the conditions of the experiment favored the formation of the thiodiazole compound.

The compound in question was subjected to the action of conc. hydrochloric acid in a sealed tube at $150^{\circ}$ and no change was observed to have taken place, except conversion into an isomeric compound of melting point $224^{\circ} .8^{\circ}$ On heating it between $190^{\circ}$ and $200^{\circ}$ for 3 hours, the molecule was, however, decomposed into hydrazine dihydrochloride, ammonium chloride, carbon disulfide and carbon dioxide. The decomposition may be explained according to the following scheme,

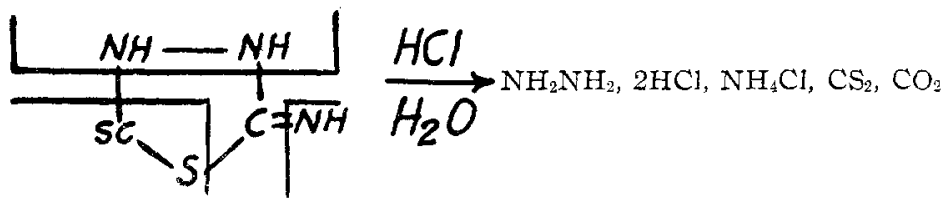

\footnotetext{
${ }^{6}$ Rây and Guha, J. Chem. Soc., 115, 261, 541 (1919).

${ }^{6}$ Freund and Imgart, Ref. 2, p. 952.

7 Busch and Wolpert, Ber., 34, 304 (1901).

${ }^{8}$ This and similar compounds, will form the subject of a subsequent communication.
} 
the rupture taking place as shown by the lines. Although it is not quite safe to lay much stress upon structural problems from the results of such a drastic treatment, the presence of carbon disulfide among the products of decomposition leads to the belief that both the atoms of sulfur are linked to the same carbon atom in the molecule.

\section{Experimental Part}

5-Amino-2-thiol-1,3,4-thiodiazole (the so-called dithio-urazole) was prepared according to the method of Freund and Ingart, ${ }^{2}$ but it has been found that the yield of the compound is about $30 \%$ greater, if instead of boiling the hydrazo-dithio-dicarbonamide with conc. hydrochloric acid for 1 hour as described by them, the heating is discontinued after 10 minutes, when a clear solution is obtained. Prolonged heating has been found to be favorable to the formation of iminothio-urazole hydrochloride at the expense of the amino-thiodiazole-thiol.

The Monosodium Salts.-These salts were prepared by adding one molecular proportion of sodium hydroxide in solution (or half a molecular proportion of sodium carbonate) to one molecular proportion of the thio compound dissolved in water or dil. alcohol and subsequently evaporating the solution to dryness.

Titration of the thio compounds with standard potassium hydroxide solution, using phenolphthalein as indicator, gave the following result.s.

Analyses. Amino-thiodiazole-thiol, $0.2016 \mathrm{~g} .: \mathrm{KOH}, 0.0845 \mathrm{~g}$; calc. for the mono salt: $0.0848 \mathrm{~g}$. Allylamino-thiodiazole-thiol, $0.1197 \mathrm{~g}$.: $\mathrm{KOH}, 0.0381 \mathrm{~g}$; ; calc. for the mono salt: $0.0387 \mathrm{~g}$. Phenylamino-thiodiazole-thiol, $0.1737: \mathrm{KOH}, 0.0464 \mathrm{~g}$; calc. for the mono salt: $0.0466 \mathrm{~g}$.

Furthermore, to verify the assertion of Freund ${ }^{4}$ that his dithio-urazole contains two atotns of hydrogen replaceable by metals, a solution of one molecular proportion of sodium carbonate was carefully added to an aqueous solution of one molecular proportion of the thio compound. The mixed solution was concentrated on the water-bath and transferred carefully to a Schrotter flask for the estimation of carbon dioxide and from this the sodium carbonate which had not reacted. Half of the sodium carbonate was fouric to have been unacted upon.

An aqueous solution of $0.4158 \mathrm{~g}$. of sodium carbonate was added to a boiling solution of $0.5214 \mathrm{~g}$. of amino-thiodiazole-thiol when carbon dioxide was evolved copiously, to the extent of $0.0906 \mathrm{~g}$. (corresponding to $0.2183 \mathrm{~g}$. of sodium carbonate). This shows that $0.1975 \mathrm{~g}$. of sodium carbonate was used up for salt formation. Formation of the mono salt requires $0.2979 \mathrm{~g}$.

Monosilver Salts.-The monosilver salt of amino-thiodiazole-thiol was prepared by adding the thio compound in aqueous solution to an excess of silver nitrate solution. The white gelatinous precipitate thus formed was carefully washed, filtered, and dried in a steam oven when it became yellow. It can also be prepared by adding silver nitrate solution to the monosodium salt.

Analyses. Subs, 0.2610: AgCl, 0.1564. Calc. for $\mathrm{C}_{2} \mathrm{H}_{2} \mathrm{~N}_{3} \mathrm{~S}_{2} \mathrm{Ag}$ : Ag, 45.00 . Found: 45.09 .

Silver Salit of Phenylamino-ThiodiazolE-Thiol.-Subs., 0.2091: Ag, 0.0725. Calc. for $\mathrm{C}_{8} \mathrm{H}_{6} \mathrm{~N}_{3} \mathrm{~S}_{2} \mathrm{Ag}$ : $\mathrm{Ag}, 34.18$. Found: 34.66 .

Silver Salt of Aliylamino-Throdiazole-Thiol.-Subs., 0.2505: Ag, 0.0986 . Calc. for $\mathrm{C}_{5} \mathrm{H}_{6} \mathrm{~N}_{3} \mathrm{~S}_{2} \mathrm{Ag}$ : Ag, 38.57. Found: 39.36 .

5-Amino-2-thiol-1,3,4-thiodiazole and mercuric nitrite. Formation of the nitromercaptide, $\left(\mathrm{C}_{2} \mathrm{H}_{2} \mathrm{~N}_{3} \mathrm{~S}\right)-\mathrm{SHgNO}_{2}$.-Analyses. Subs., 0.2154: $\mathrm{HgS}, 0.1307 ; \mathrm{BaSO}_{4}$, 
0.2730. Subs., 0.1373: 17.6 cc. $\mathrm{N}_{2}\left(30^{\circ}\right.$ and $761 \mathrm{~mm}$.). Calc. for $\mathrm{C}_{2} \mathrm{H}_{2} \mathrm{O}_{2} \mathrm{~N}_{4} \mathrm{~S}_{2} \mathrm{Hg}$ : $\mathrm{N}, 14.81 ; \mathrm{S}, 16.93 ; \mathrm{Hg}, 52.91$. Found: $\mathrm{N}, 14.29 ; \mathrm{S}, 17.41 ; \mathrm{Hg}, 52.31$.

The above Nitromercaptide and Ethyl Iodide. Formation of the Compound R.Et $\mathrm{S}_{2}, \mathrm{HgI}_{2}, \mathrm{EtI} .^{9}$-The nitromercaptide was heated under a reflux condenser with ethyl iodide until a clear solution was obtained; ethyl iodide was then removed by evaporation. The oily product was dissolved in acetone, filtered and precipitated by benzene and this process was repeated several times to obtain the compound in a pure state.

Analyses. Subs., 0.2011: $\mathrm{CO}_{2}, 0.0685$. Subs, $0.1900: 9.3 \mathrm{cc} . \mathrm{N}_{2}\left(31^{\circ}\right.$ and 759 mm.). Subs., 0.2531: $\mathrm{Hg}, 0.0645$; AgI, 0.2622. Calc. for $\mathrm{C}_{6} \mathrm{H}_{12} \mathrm{~N}_{3} \mathrm{I}_{3} \mathrm{~S}_{3} \mathrm{Hg}$ : C, 8.96; $\mathrm{N}, 5.23 ; \mathrm{I}, 47.44 ; \mathrm{Hg}, 24.91$. Found: $\mathrm{C}, 9.33 ; \mathrm{N}, 5.42 ; \mathrm{I}, 47.56 ; \mathrm{Hg}, 25.48$.

5-Amino-2-thiol-1,3,4-thiodiazole and Iodine.-The thio compound was dissolved in about $300 \mathrm{cc}$. of hot water. The solution was cooled to a temperature of about $30-35^{\circ}$ and an excess of $0.1 \mathrm{~N}$ iodine solution was adder. The excess of iodine was then titrated with standard $0.1 \mathrm{~N}$ thiosulfate solution.

To $0.1561 \mathrm{~g}$. of the thio compound was added $13.8 \mathrm{cc}$. of the iodine solution, the excess requiring $2.15 \mathrm{cc}$. of the thiosulfate solution; therefore $0.1561 \mathrm{~g}$. of the thio compound required $0.1477 \mathrm{~g}$. of iodine. Formation of $\left(\mathrm{C}_{2} \mathrm{H}_{2} \mathrm{~N}_{3} \mathrm{~S}\right)-\mathrm{S}-\mathrm{S}-\left(\mathrm{C}_{2} \mathrm{H}_{2} \mathrm{~N}_{3} \mathrm{~S}\right)$ requires $0.1499 \mathrm{~g}$. Freund's azo formula, $\mathrm{C}_{2} \mathrm{HN}_{3} \mathrm{~S}_{2}$, requires $0.2998 \mathrm{~g}$.

5-Phenylamino-2-thiol-1,3,4-thiodiazole and Iodine.-To $0.2427 \mathrm{~g}$. of the thio compound dissolved in $20 \%$ alcohol was added $24.6 \mathrm{cc}$. of iodine solution, the excess requiring $13.5 \mathrm{cc}$. of the thiosulfate solution. Therefore $0.2427 \mathrm{~g}$. of the thio compound required $0.1410 \mathrm{~g}$. of iodine. Formation of $\left(\mathrm{C}_{2} \mathrm{HPhN}_{3} \mathrm{~S}\right)-\mathrm{S}-\mathrm{S}-\left(\mathrm{C}_{2} \mathrm{HPhN}_{3} \mathrm{~S}\right)$ requires $0.1474 \mathrm{~g}$. Freund's azo formula, $\mathrm{C}_{2} \mathrm{PhN}_{3} \mathrm{~S}_{2}$, requires $0.2948 \mathrm{~g}$.

5-Allylamino-2-thiol-1,3,4-thiodiazole and Iodine.-To $0.3800 \mathrm{~g}$. of the substance in aqueous alcoholic solution was added $33.1 \mathrm{cc}$. of the iodine solution, the excess requiring $11.60 \mathrm{cc}$. of the thiosulfate solution. Therefore $0.3800 \mathrm{~g}$, of the thio compound required $0.2730 \mathrm{~g}$. of iodine. Formation of $\left(\mathrm{C}_{2} \mathrm{H} . \mathrm{C}_{3} \mathrm{H}_{5} \mathrm{~N}_{3} \mathrm{~S}\right)-\mathrm{S}-\mathrm{S}-\left(\mathrm{C}_{2} \mathrm{H} . \mathrm{C}_{3} \mathrm{H}_{5} \mathrm{~N}_{8} \mathrm{~S}\right)$ requires $0.2790 \mathrm{~g}$. Freund's azo formula, $\mathrm{C}_{2} \mathrm{C}_{3} \mathrm{H}_{5} \mathrm{~N}_{3} \mathrm{~S}_{2}$, requires $0.5580 \mathrm{~g}$.

Analysis. Mol. wt.:0.9915 g. of the disulfide in $13.8 \mathrm{~g}$. of alcohol gave an elevation of $0.23^{\circ}$. Calc. for $\mathrm{C}_{10} \mathrm{H}_{12} \mathrm{~N}_{6} \mathrm{~S}_{4}$; mol. wt., 344 ; calc. for Freund's azo ${ }^{10}$ formula, 171 . Found: 359 (another determination gave 351 ).

Analysis. Hydrogen." ${ }^{11}$ Subs., 0.1513: $\mathrm{H}_{2} \mathrm{O}, 0.0212$. Two other analyses gave $\mathrm{H}, 1.49 ; 1.68$ per cent. Calc. for $\mathrm{C}_{4} \mathrm{H}_{4} \mathrm{~N}_{6} \mathrm{~S}_{4}: \mathrm{H}, 1.52$. Found: 1.56 (by two other analyses, $1.49,1.68$ ). Freund's azo formula, $\mathrm{C}_{2} \mathrm{HN}_{3} \mathrm{~S}_{2}$, requires 0.76 .

The estimation of hydrogen was made with special care to guard against moisture. Preceding each analysis a blank experiment was performed as a check.

Decomposition of 5-Amino-2-thiol-1,3,4-thiodiazole by the Action of Hydrochloric Acid.-The thio compound was heated in a sealed tube with conc. hydrochloric acid (sp. gr. 1.16) at $190-200^{\circ}$ for 3 hours. A white crystalline substance and oily globules were formed, with an excess of hydrogen sulfide and carbon dioxide as gases. The contents of the tube were filtered and drained by suction. In the filtrate were oily

${ }^{9}$ Cf. Rây, J. Chem. Soc., 109, 698 (1916).

${ }^{10}$ Freund and Heilbrun (Ref, 2, p. 861) gave the mol. wt. of the disulfide of their ethyl-dithio-urazole (basic), taken in glacial acetic acid solution by the ebullioscopic method, as 175 and their formula required 159 . This must obviously be due either to an error of experiment or to some sort of dissociation of the molecule.

${ }^{11}$ Freund and Heilbrun (Ref. 2, p. 862) gave the percentage of hydrogen in the disulfide of their allyldithio-urazole as 3.73 ; the calculated value for their formula is 2.92 , and that for the new formula, $\mathrm{C}_{10} \mathrm{H}_{12} \mathrm{~N}_{6} \mathrm{~S}_{4}$, is 3.49 . The percentage of hydrogen found by them evidently supports the new formula. 


$$
\text { CONSTITUTION OF DITHIO-URAZOLE }
$$

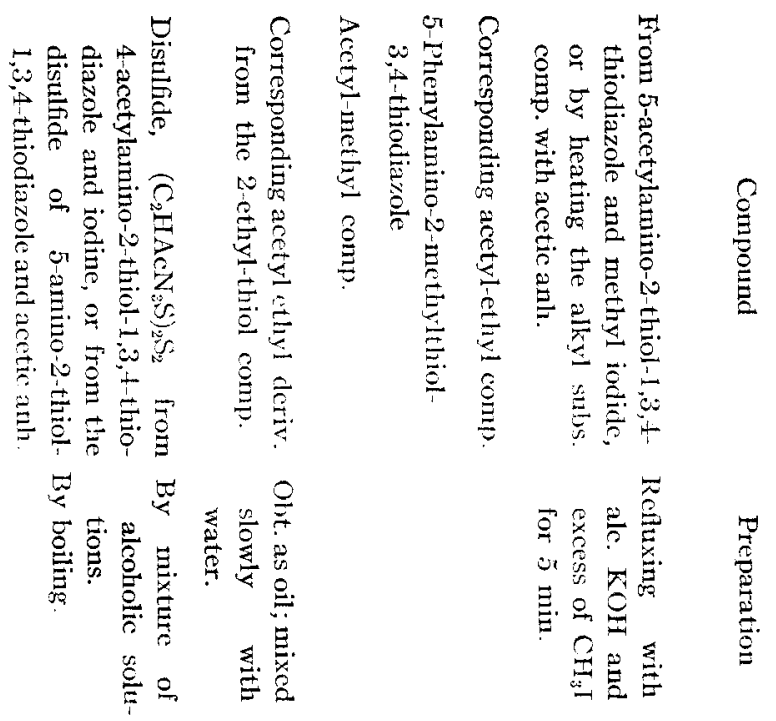

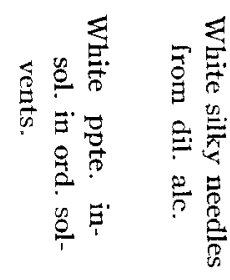

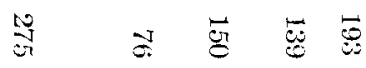

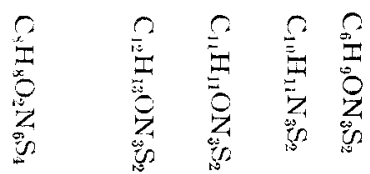

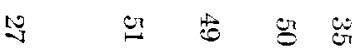

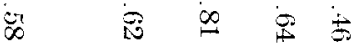

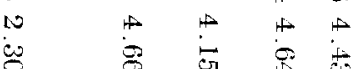

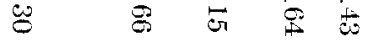

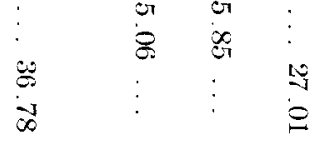

ज

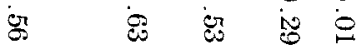

$1+\infty$ u

\& $\infty$ \& 8

$\overrightarrow{\mathrm{c}} 5$

is $i$

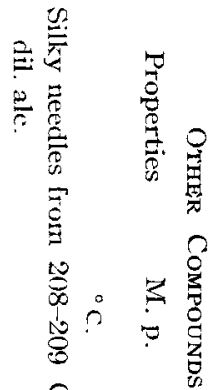

品高

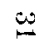

in

$\omega$

거

量 20

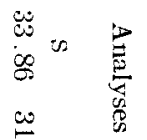

$\frac{\omega}{\infty}{ }^{\infty}$

ஸ

고

蕰

$\infty$

$\stackrel{\infty}{\infty}$

$\stackrel{\leftrightarrow}{\infty}$ 
globules of carbon disulfide containing dissolved sulfur; the aqueous solution contained ammonium chloride. The residue on the filter paper was crystallized from water, and gave silver chloride with silver nitrate, but no ammonia when boiled with alkali. The substance melted at $198^{\circ}$ (m. p. of hydrazine dihydrochloride) and reduced Fehling's solution.

The author takes this opportunity of expressing his sincere thanks to Sir P. C. Rây and to Dr. P. C. Mitter for the kind interest they have shown during the progress of the work.

Calcutra, INDia

[CONTRibution From the Chemical Laboratory of the University College of SCIENCE OF CALCUT'TA]

\title{
CONSTITUTION OF THE SO-CALLED DITHIO-URAZOLE OF MARTIN FREUND. II. NEW METHODS OF SYNTHESIS, ISOMERISM AND POLY-DERIVATIVES
}

\author{
By Praphulia Chandra Guha \\ Received January 31, 1921
}

In Part $I,{ }^{1}$ the author put forward the amino-thiodiazole-thiol formula for the so-called dithio-urazole based upon the action of mild oxidizing agents such as iodine, ferric chloride, hydrogen peroxide; action of alkali, alkyl iodides, mercuric nitrite and on the different behaviors of the mono acyl and mono alkyl derivatives and so on. In the present paper a number of new methods for the synthesis of the parent amino-thiodiazole-thiol (the so-called dithio-urazole) and its mono- and di-derivatives will be described. These, it is expected, will throw additional light upon the problem of the constitution of this substance.

Up to the present time, only one method for the preparation of the so-called dithio-urazoles has been known, and that is by the elimination of ammonia from hydrazo-dithio-dicarbonamides by the action of conc. hydrochloric acid, when, simultaneously, imino-thio-urazole hydrochloride is formed with the elimination of a molecule of hydrogen sulfide. ${ }^{2}$ It may be mentioned here that no method is known by which 3,5-disubstituted compounds can be prepared, either directly by synthesis or by subsequent introduction of groups into the parent thiodiazole molecule.

When thiosemicarbazide is treated with alcoholic potassium hydroxide and carbon disulfide, there is formed at first potassium hydrazothiocarbonamide dithiocarboxylate $\left(\mathrm{NH}_{2} \mathrm{CSNHNHCSSK}\right)$. On raising the temperature of the reaction this potassium salt yields the potassium salt of a new closed-ring compound which has been found to be amino-thiodiazolethiol (the so-called dithio-urazole).

${ }^{1}$ Guha, This Journal, 44, 1502 (1922).

2 Freund and Imgart, Ber., 28, 946 (1895). 